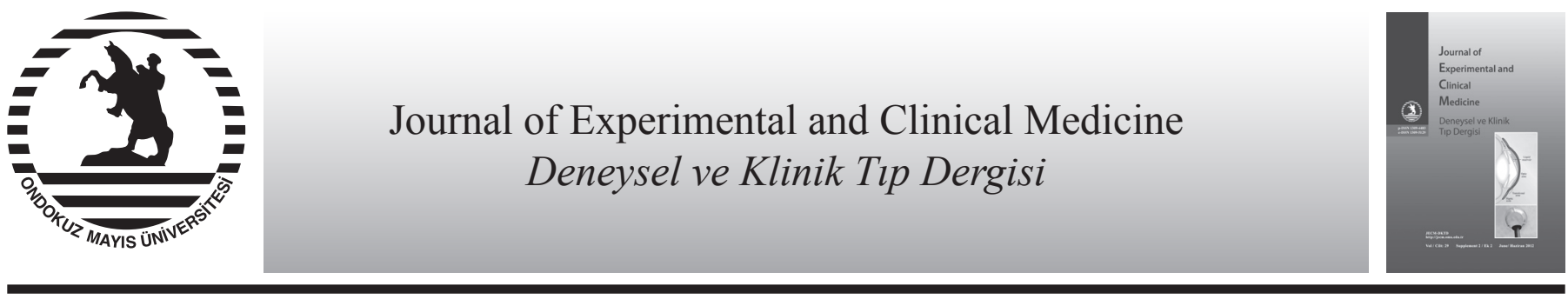

Derleme / Review doi: $10.5835 /$ jecm.omu.29.s2.006

\title{
Neovasküler yaşa bağlı makula dejenerasyonunda anti-vasküler endotelyal growth faktör tedavi protokolleri
}

\author{
Anti-vascular endothelial growth factor treatment strategies for neovascular age-related macular degeneration
}

Hakkı Birinci

Ondokuz Mayıs Üniversitesi, Tıp Fakültesi, Göz Hastalıkları Anabilim Dalı, Samsun, Türkiye

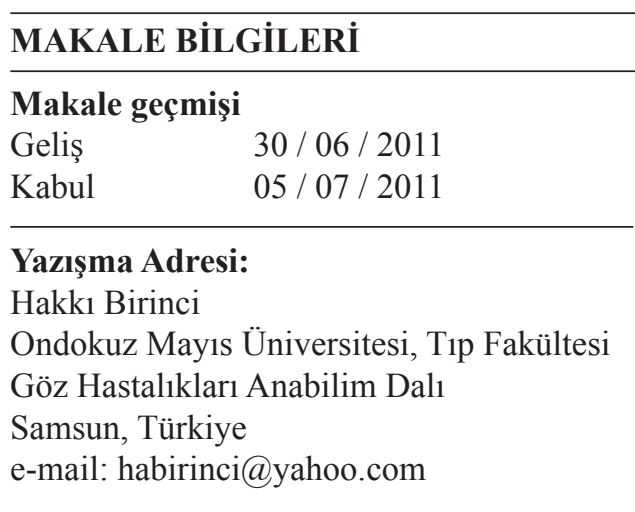

\section{Anahtar Kelimeler:}

Yaşa bağlı makula dejenerasyonu Vasküler endotelyal growth faktör (VEGF) Neovaskülarizasyon

Ranibizumab

\section{Keywords:}

Age-related macular degeneration

Vascular endothelial growth factor (VEGF)

Neovascularisation

Ranibizumab

\section{ÖZET}

Vasküler endotelyal growth faktör-A'nın (VEGF-A) neovasküler tip yaşa bağlı makula dejenerasyonunda (YBMD) neovaskülarizasyondan sorumlu en önemli anjiyojenik uyaran olduğu ortaya konulmuştur. Bu tespitten sonra özellikle son 10 yılda neovasküler tip YBMD tedavisinde önemli gelişmeler kaydedilmiştir. VEGF-A antagonistleri neovasküler tip YBMD tedavisinde yaygın olarak kullanılmaya başlamıştır. Ranibizumab, neovasküler YBMD tedavisinde yasal olarak kabul edilen en etkin antagonistidir. ANCHOR ve MARINA çalışmalarında intravitreal ranibizumabın aylık uygulandığında neovasküler tip YBMD’nin tüm tiplerinde etkili olduğu gösterilmiştir. Bu iki pilot çalışmada ilk üç dozu takiben, aylık devam eden enjeksiyonlar ile görme keskinliğinin en iyi şekilde sağlandığı gösterilmiştir. Ancak, sürekli aylık enjeksiyona devam etmek mümkün değildir, bunun yerine lezyon aktivitesine göre hastaların takibi ve gerektiğinde tedavi uygulanabilecek esnek tedavi protokolleri önerilmektedir. Başlangıçta ilk 3 ay enjeksiyon genel kabul görmüştür. Sonrasında dikkatli takip ve esnek bir tedavi protokolü görme kaybını engelleyebilecektir. Bu çalı̧̧mada neovasküler tip YBMD tedavisinde esnek tedavi protokollerinin sonuçlarının ortaya konulması, takip ve tedavi parametrelerinin araştırılması amaçlanmıştır.

J. Exp. Clin. Med., 2012; 29:S81-S84

\section{ABSTRACT}

Vascular endothelial growth factor-A (VEGF-A) has been implicated as the major angiogenic stimulus responsible for neovascularisation in neovascular age-related macular degeneration. The past decade has been one of great progress for the treatment of neovascular age-related macular degeneration (AMD). Pharmacotherapy against VEGF-A have been introduced to treat neovascular AMD. Ranibizumab at the moment appears to be the most effective approved treatment for neovascular AMD. The benefits of intravitreal ranibizumab apply to all angiographic subtypes of neovascular AMD when the drug is injected at monthly intervals as shown ANCHOR and MARINA study. Treatment initiation with three consecutive monthly injections, followed by continued monthly injections, has provided the best visual acuity outcomes in pivotal cliniveal trials. If continued monthly injections are not feasible after initiation, a flexible strategy appears viable, with monthly monitoring of lesion activity recommended. Initiation regimens of fewer than three injections have not been assessed. Continuous careful monitoring with flexible treatment may help avoid vision loss recurring. The aim of this study was to analyse results of flexible anti- VEGF treatment in neovascular age-related macular degeneration, and to search for parameters with impact on outcome.

J. Exp. Clin. Med., 2012; 29:S81-S84

(C) 2012 OMU
Yaşa bağlı makula dejenerasyonu (YBMD) gelişmiş ülkelerde 60 yaş üzeri kişilerde görme bozukluklarının ve görme kaybının en sık nedenlerinden biridir. YBMD'li hastaların \%10-15'inde ağır görme kaybı gelişmektedir. Nonneovasküler formda \%20-25, neovasküler formda yaklaşık
\%70 oranında ağır görme kaybı gelişmektedir (Karaçorlu ve ark., 2009).

Vasküler endotelyal growth faktör (VEGF) anjiyogenezis ve vasküler permeabilite düzenlenmesinde önemli rol oynar. Fizyolojik rolünün yanı sıra tümörlerin anjiyogenezisinde, 
YBMD, diyabetik retinopati ve prematüre retinopatisi gibi neovasküler göz hastalıklarının patogenezisinde de önemli bir rol oynar. VEGF-A anjiyogeneziste ve vasküler permeabilitede en önemli rolü oynar (Spitzer ve ark., 2008).

Neovasküler tip YBMD tedavisinde son yıllarda kullanılmaya başlayan antianjiyojenik ilaçlar yüz güldürücü sonuçlar ortaya koymuş, görme kaybının durdurulması sağlanmış, hatta bir miktar görme artışı oluşturmuşlardır. Bugün için koroidal neovaskülarizasyon tedavisinde kullanılabilecek üç VEGF inhibitörü mevcuttur. İlk olarak kullanıma giren pegaptanib sodyum VEGF-A 165'i bloke eden bir VEGF aptameridir. Kontrol grubuna göre görme kaybında anlamlı azalma oluşturduğu ortaya konulmasına karşın tüm VEGF-A izomerlerini bloke eden diğer iki ajana oranla etkinliği daha azdır (Karaçorlu ve ark., 2009; Rosenfeld ve ark., 2006). Esas olarak kolorektal kanserlerde metastatik anjiyogenezis inhibisyonunda kullanılan ve oküler kullanım için onayı bulunmayan bevacizumab aktif VEGF-A izomerlerinin hepsini bloke eder. Oküler kullanım için oluşturulmuş ranibizumabın ise molekül ağırlığı bevacizumabın 1/3'ü kadardır, ve VEGF bağlanma özelliğinin daha fazla olduğu düşünülmektedir. Ranibizumab tüm aktif VEGF-A izoformlarına bağlanarak onları inhibe eden humanize edilmiş bir monoklonal antikor parçasıdır. Molekülün retinaya kolaylıkla geçebilmesi için boyutları da küçültülmüştür. Ranibizumab retina içine penetrasyonu artırmak amacıyla bütün antikor olarak değil, antikor parçası olarak üretilmiştir (Mitchell ve ark., 2010; Rosenfeld ve ark., 2006).

Tablo 1. Yaş tip YBMD'de sham grubuna göre ranibizumabın etkinliğinin karşılaştırılması (MARINA Çalışması)

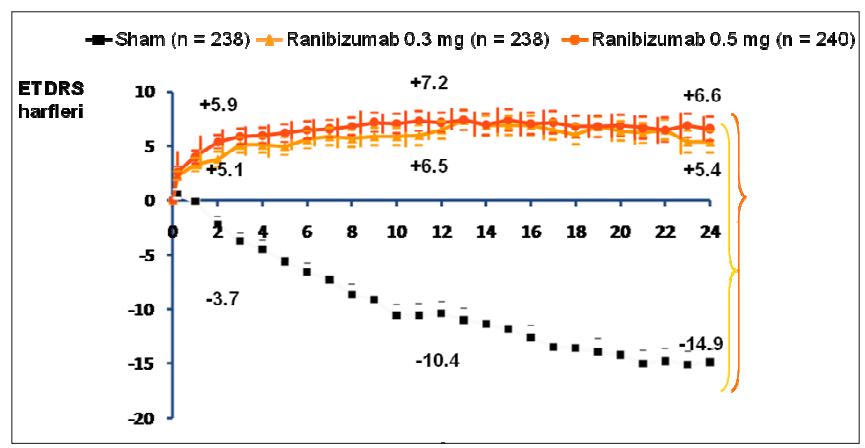

Tüm karşılaştırmalarda sham'e karşı ranibizumab için $p<0,001$ ETDRS, early treatment diabetic retinopathy study. (Rosenfeld ve ark, 2006)

Ranibizumabın etkinliğini ortaya koyan ilk kontrollü çalışmalar MARINA (Rosenfeld ve ark., 2006) ve ANCHOR (Brown ve ark., 2006) çalışmalarıdır. Bu çalışmalarda aynı zamanda doz ve güvenlik araştırması da yapılmıştır. MARINA çalışmasında minimal klasik ve gizli koroidal neovasküler membran (KNVM) olan hastalarda $0,3 \mathrm{mg}$ ve $0,5 \mathrm{mg}$ dozlarında ayda bir 24 ay süre ile intravitreal olarak uygulanmış ve 24 ayın sonunda $0,5 \mathrm{mg}$ ranibizumab uygulanan grupta 6,6 ve $0,3 \mathrm{mg}$ ranibizumab uygulana grupta 5,4 harf kazanımı sağlanmıştır. Kontrol grubunda ise 14,9 harf kaybı oluşmuştur. MARINA çalışmasının sonuçları Tablo 1'de gösterilmiştir. $\mathrm{Bu}$ çalışmada sham grubuna göre tüm aylarda görmede anlamlı artış tespit edilmiştir.

ANCHOR çalışmasında ise baskın klasik KNVM olan hastalara 0,3 ve $0,5 \mathrm{mg}$ ranibizumab uygulanmış ve fotodinamik tedavi (PDT) yapılan hastalar ile kıyaslanmıştır. Bu çalışmada amaç ayda bir uygulanan intravitreal ranibizumab enjeksiyonlarının görme kaybını önlemedeki etkinliğini PDT ile karşılaştırmak ve ayda bir ranibizumab tedavisinin etkinlik ve güvenliliğini araştırmaktı. 24 ay süre ile her ay intravitreal ranibizumab injeksiyonu yapılmış, kontrol grubunda ise ihtiyaca göre üç ayda bir PDT yapılmıştı. Sonuç olarak 24 ayın sonunda $0,5 \mathrm{mg}$ ranibizumab uygulanan grupta 10,7 harf kazanımı ve 0,3 mg ranibizumab uygulanan grupta 8,1 harf kazanımı, PDT yapılan grupta ise 9,8 harf kaybı oluşmuştur. Sonuçlar Tablo 2'de gösterilmiştir.

$\mathrm{Bu}$ çalışmalarda ranibizumabın etkinliği ve güvenliği açık şekilde ortaya konulmuş, ilk kez bu grup hastalarda görme artışı sağlanabilmiş ve neovasküler YBMD tedavisinde yeni bir dönem başlamıştır. Bu çalışmalarda 1. aydan itibaren görme artışı sağlanmış ve 3. ayın sonunda görme artışı en yüksek seviyesine ulaşmıştır. Daha sonraki aylık uygulamalar ile kazanılan görme artışı korunmuştur.

Tablo 2. Yaş tip YBMD'de PDT ve ranibizumabın etkinliğinin karşılaştırılması (ANCHOR Çalışması)

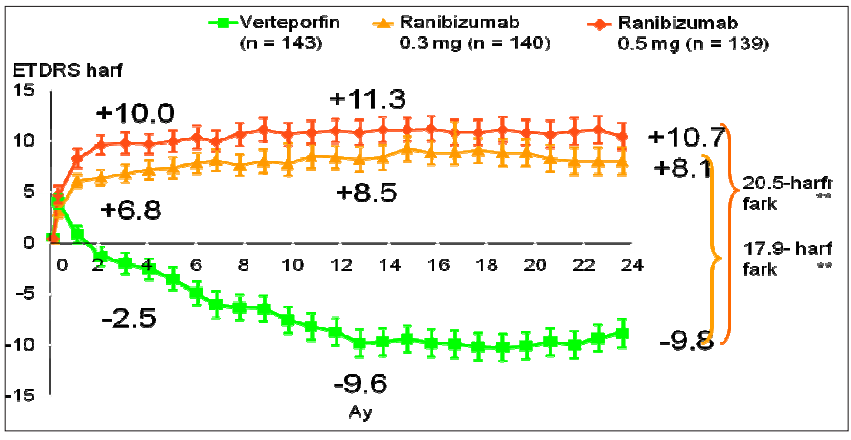

$p<0,001$ vs verteporfin PDT, her ay için; ETDRS, Early Treatment Diabetic Retinopathy Study (Brown ve ark, 2006).

YBMD tanısı ve tedavisi daha önceki klinik çalışmalarda flöresein anjiyografi sonuçlarına dayanmakta idi. Son yıllarda ise tedaviye karar vermede ve hastalığın tanısı ve takibinde optik koherens tedavi (OCT) önemli yer almaya başlamıştır. Ancak alınan kesitlerin aynı bölgelerden geçtiğine dikkat etmek gerekir.

MARINA ve ANCHOR çalışmaları aylık uygulama ile ranibizumabın yaş tip YBMD tedavisinde oldukça etkili olduğunu ortaya koymuştur, ancak aylık tedavinin hem uygulamadaki zorluklar hem de maddi olarak büyük maliyet gerektirdiği için sürekli olarak devam edilebilmesi mümkün değildir. İnjeksiyonların sıklığı ve süresi henüz tam olarak aydınlatılamamıştır. $\mathrm{Bu}$ nedenle hem uygulama ve kontrol sayısını azaltacak, hem de tedavi etkinliğini aylık tedavideki başarıya yakın tutacak yeni tedavi şemaları arayışları ortaya çıkmıştır. Bu çalışmalarda en az doz, en az vizit, etkin tedavi planlaması, nükslerin engellenmesi veya erken tanısını ortaya koyacak protokoller araştırılmıştır. Bu tür çalışmalar bireyselleştirilmiş tedavi protokolü olarak da isimlendirilmiştir. Bireyselleştirilmiş tedavi protokolleri başlıca 3 grup altında toplanabilir

1- 3 ay ara ile kontrol ve her kontrolde tedavi: PIER, EXCITE

2- Düzenli kontrol ve gerektiğinde tedavi çalışmaları; 
(PRN (Pro Re Nata), Tedavi et ve Gözle)

3- Tedavi et ve uzat (Treat and extend)

\section{PIER çalıșması}

KNVM'nin tüm alt tiplerinin alındığı bir çalışma olarak planlanıp, ilk 3 ay ayda bir yükleme dozunu takiben hastalar üçer ay ara ile görülüp her kontrolde tedavi uygulandi. Kontrol grubunda ise aynı zaman aralıkları ile çağrılıp sham injeksiyonu yapıldı. Çalışma 24 ay süre ile uygulandı ve sonuç olarak sham grubuna göre görme kaybında anlamlı olarak azalma tespit edilmesine rağmen, yükleme dozunu takiben kazanılan görmenin 2 yıl süresince azalarak yaklaşı başlang1ç görme düzeylerine döndüğü tespit edilmiştir (Regillo ve ark., 2008; Abraham ve ark., 2010). Sonuçlar Tablo 3 'te gösterilmiştir.

Tablo 3. PIER çalışmasında 3 ay ara ile yapılan tedavinin görme keskinliği sonuçları (Abraham ark. 2010).

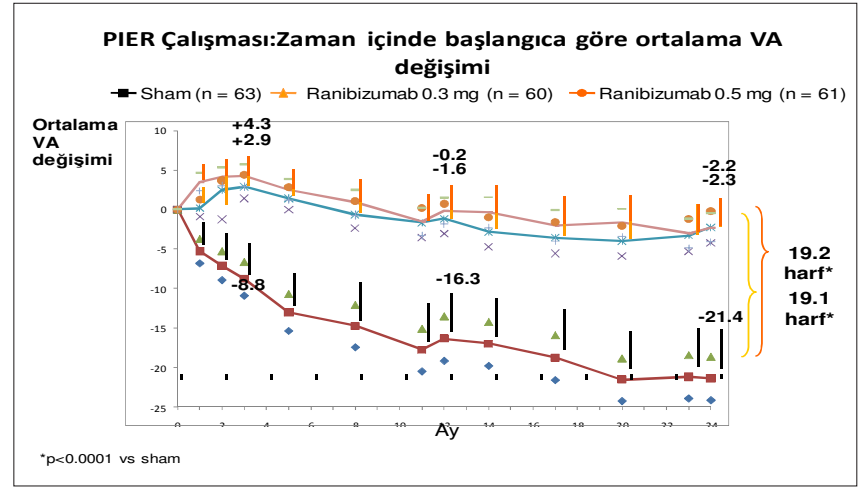

EXCITE çalışması (Schmidt-Erfurth ve ark., 2011)

KNVM'lerin tüm alt tipleri çalışma kapsamına alınmış ve çalışma ilk 3 yükleme dozunu takiben 3 aylık ranibizumab injeksiyonları yapılarak bir yılda tamamlanmıştır. $0,3 \mathrm{mg}$ ve 0,5 mg ranibizumab ve aynı tedavi şeması ile sham injeksiyonu yapıldı. Bir grupta ise aylık injeksiyonlara 1 yıl boyunca devam edildi. Aylık injeksiyon yapılan grupta bir yılın sonunda 8,3 harf kazanımı, 3 ayda bir tedavi uygulanan grupta $0,3 \mathrm{mg}$ ranibizumab uygulananlarda 3,8 harf, $0,5 \mathrm{mg}$ ranibizumab uygulananlarda ise 4,9 harf kazanımı olduğu tespit edilmiştir. Bu çalışmada 3 ay ara ile yapılan injeksiyonlar ile PIER çalışmasına gore daha başarılı bir sonuç elde edilse de aylık injeksiyonlar ile tedavi edilen grupta sonuçlar anlamlı olarak daha iyi idi.

\section{PRN protokolleri}

Tedavi planlaması OCT rehberliğinde yapılmaktadır (Lalwani ve ark., 2009). Tedavi et ve izle protokolünü takip eden bu çalışmalarda 3 aylık injeksiyonundan sonra OCT'de santral retinal kalınlıkta $\geq 100 \mu \mathrm{m}$ artış, OCT ile makulada sıvı bulgusu ile birlikte $\geq 5$ harf kaybı, yeni makuler kanama, yeni klasik koroidal neovaskülarizasyon (KNV) alanı, önceki enjeksiyondan sonra OCT ile $\geq 1$ ay süreyle kalıcı sıvı bulgusu görüldüğünde yeniden tedavi edilmiştir. Lezyon kuru ise düzenli aralıklarla takip önerilmektedir.

PRN protokolleri esas alınarak yapılan başlıca çalışmalar; PrONTO (Lalwani ve ark., 2009), SAILOR 1.kolu (Rosenfeld ve ark., 2006), SUSTAIN (Holz ve ark., 2011) çalışmalarıdır.

\section{PrONTO çalışması}

İki yıllık, açık etiketli, prospektif, randomize olmayan, tek merkezli bir çalışmadır. YBMD’ye sekonder subfoveal KNVM (tüm lezyon tipleri) çalışma kapsamına alınmış ve tüm hastalarda başlangıç OCT santral retina kalınlığ $1 \geq 300$ $\mu \mathrm{m}(\mathrm{n}=40)$ olarak planlanmıştır. Tüm hastalarda ilk 3 yükleme dozu yapılmış ve sonrasında değerlendirmeler ve bireyselleştirilmiş OCT rehberliğinde gerekli görülürse yeniden ranibizumab tedavisi uygulanmıştır.

24 ayın sonunda 40 hastanın 37'si ile çalışma tamamlanmış ve ortalama görme kazanımı 1. yılın sonunda 9,3 harf, 2. yılın sonunda 11,1 harf olarak bulunmuştur. İki yılda 9,9 enjeksiyon $(5,6+4,3)$ ile tedavi sağlanmıștır.

Değişken tedavi şeması ile (Ranibizumab 0,5 mg), PrONTO çalışmasında daha az intravitreal enjeksiyon sayısı ile 24 ayda aylık doz rejimlerine benzer etkinlik sonuçları elde edilmiştir. PrONTO çalışmasının 1 yıllık sonuçları Tablo 4'de gösterilmiştir

\section{SUSTAIN çalışması}

50 yaş üstü YBMD’ye bağlı KNVM olan 513 hasta çaış̧ma kapsamına alınmıştır. Çalışmada KNVM tipi ayırt edilmemiştir. İlk 3 aylık yükleme dozunu takiben, aylık takip yapılarak gerektiğinde PRN kriterlerine göre tedavi uygulanmıştır. İlk yıl sonunda hastalara ortalama 5,7 injeksiyon yapılmış, görme kazanımı en iyi 3. ayın sonunda ve 5,8 harf olarak bulunmuştur. Sonra hafif azalarak ilk yılın sonunda ortalama 3,6 harf kazanımı olmuştur. İlk 3 ay kazancı çoğu olguda korunmuştur. Bu çalışmada \%20 olguda tekrar injeksiyona gerek duyulmamıştır ve her olgunun tedavi gereksinimi farklı olduğu ifade edilmiştir.

Tablo 4. PrONTO çalışmasının ilk yılında görme keskinliği sonuçları (Fung ve ark. 2007).

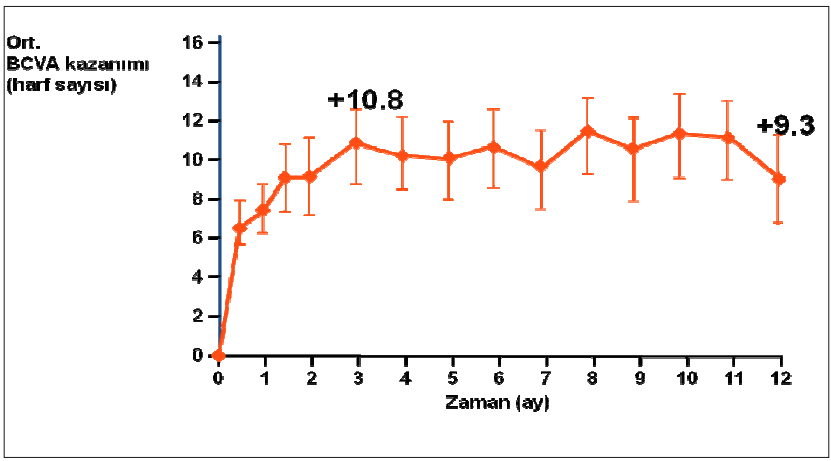

PRN tedavi kriterleri uygulanan bir çalışmada; (Gerding ve ark., 2011) ilk 3 aylık yükleme dozu sonra aylık takip ve gerektiğinde ek tedavi yapılmış ve 12 ay sonunda ortalama 5,8 injeksiyon ve ortalama 5,0 harf kazanç oluşmuştur. Bu çalışmada tedaviye cevaba göre hastalar winner, stabilizer ve loser olarak 3 gruba ayrılmıştır. Winner grupta ilk 3 ayda görmenin önemli oranda arttığı ve sonrasında bu görme artışının korunduğu, stabilizer grupta başlangıçta az bir artış oluşmasına rağmen sonra azalarak yaklaşık başlangıç görme düzeylerinin korunduğu, looser grupta ise tedaviye rağmen görmede azalmanın gittikçe arttığı ortaya konmuştur.

PRN kriterlerine göre tedavi yapılan hastalarda; tekrarlayan retina içi ya da altı sıvı birikimi sonuçta nöral retinada kalıcı işlev kaybına yol açabileceği, tedavinin sürdürülmesi- 
ne karşın görme artmayabileceği ve OCT değerlendirmesinde 100 mikron sınırının hatalara yol açabileceği de ifade edilmektedir.

\section{Tedavi et ve uzat (treat and extend) protokolleri}

Tüm hastalara lezyon kuruyuncaya kadar aylık tedavi uygulanır, OCT rehberliğinde kontroller yapılır. Kontrolde aktivasyon yoksa tedavi yapilıp ara 2 hafta uzatılır. Her vizitte lezyon kuru da olsa mutlaka tedavi yapılır ve ara en fazla 3 ay olacak şekilde uzatılır. Nüks varsa tedavi yapılıp ara 2 hafta kısaltılır.

Gupta ve ark. (2010) 92 vakadan oluşan çalışmalarında 'tedavi et ve uzat' protokolü ile 2 yılda görme kazanımını 9,7 harf olarak elde etmişler ve ara ortalama 80 güne kadar uzatılabilmiştir. Ortalama injeksiyon sayısı ilk yıl 8,4, ikinci y1l 7,5 olarak bulunmuştur. Nüks değerlendirilmesinde ise $\% 45$ nüks yok, $\% 30$ bir nüks ve $\% 7$ vakada sürekli sıvı tespit edilmiştir (2011).

Oubraham ve ark. ise PRN ve tedavi et uzat protokolü uygulanan iki grup oluşturarak sonuçları karşılaştırdılar. İki grupta da standart 3 injeksiyonu takiben PRN grupta 5 haftada bir kontrol gerekirse tedavi uygulandı. 'Tedavi et uzat' grupta nüks yoksa bile tedavi yapılıp kontrol 2 hafta uzatıl- d1 ve ara en fazla 12 hafta uzatıldı. 12 ayın sonunda görme kazanımı, PRN +2,3 +/-17,4 ve tedavi et uzat $+10,8+/-8,8$ olarak bulundu. Enjeksiyon sayısi: PRN 5,2 tedavi et uzatta 7,8 , vizit sayıs ise PRN 8,8 tedavi et uzat 8,5 olarak tespit edilmiștir.

Sonuç olarak; yaş tip YBMD tedavisinde en iyi sonuç aylık enjeksiyonlar ile sağlanabilmektedir. Ancak hem maliyeti çok yüksek hem de uygulanabilirliği gerçekçi değildir. $\mathrm{Bu}$ nedenle farklı tedavi stratejileri arayışları olmuştur. Yükleme dozunu takiben 3 aylik ara ile yapılan injeksiyonlar ile de görme kazanımı tatmin edici değildir. PRN tedavi protokolü olarak tanımlanan ilk 3 tedaviden sonra uygun aralıklar ile kontrol ve gerektiğinde tedavi yapılan hastalarda iyi sonuçlar elde edilmiş ve bazı çalışmalarda aylık enjeksiyonlara yakın sonuçlar bildirilmiştir. Ancak bu grupta da nüks oluşumuna izin verilmesi ve bazı hastalarda kalıcı görme kaybı gelişmesi protokolün eksik yönlerini oluşturmaktadır. Tedavi et ve uzat protokolleri ile de iyi sonuçlar bildirilmesine rağmen tedavi sayısında önemli tasarruf sağlanamamıştır. Bütün tedavi protokollerinde ilk 3 ay uygulanan yükleme dozu genel kabul görmektedir ve görme kazanımının en yüksek 3. ayın sonunda olduğu vurgulanmaktadır.

\section{KAYNAKLAR}

Abraham, P., Yue, H., Wilson, L., 2010. Randomized, double-masked, sham-controlled trial of ranibizumab for neovascular age-related macular degeneration: PIER Study year 2. Am. J. Ophthalmol. 150, 315-24.

Brown, D.M., Kaiser, P.K., Michels, M., For the ANCHOR study Group. 2006. Ranibizumab versus verteporfin for neovascular age-related macular degeneration. The New England Journal of Medicine. 35, 1432-44.

Gerding, H.,Loukopoulos, V., Riese, J., Hefner, L., Timmermann, M., 2011. Results of flexible ranibizumab treatment in age-related macular degeneraion and search of parameters with impact on outcome. Graef. Arch. Clin. Exp. Ophthalmol. 1636-1646.

Gupta, O.P., Shienbaum, G., Patel, A.H., Fecarotta, C., Kaiser, R.S., Regillo, C.D., 2010, A treat and extent regimen using ranibizumab for neovascular age-related macular degeneration. 117, 2134-2140.

Holz, F.G., Amoaku, W., Donate, J., Guymer, R.H., Kellner, U., Schlindemann, R.O., 2011. Safety and efficacy of a flexible dosing regimen of ranibizumabin neovascular age-related macular degeneration: The SUSTAIN Study. Ophthalmology. 118, 663-671.

Karaçorlu, M., Karaçorlu, S.A., Özdemir, H., 2009. Yaşa bağlı makula dejenerasyonu ve anti-VEGF tedavi. Göz hastalıkları ve anti-VEGF tedavi.

Lalwani, G.A., Rosenfeld, P.J., Fung, A.E., Dubovy, S.R., Michels, S., Feuer, W., 2009.A variable-dosing regimen with intravitreal ranibizumab for neovascular age-relatedmacular degeneration:Year 2 of the PrONTO Study. Am. J. Ophthalmol. 148, 43-58.

Mitchell, P., Korobelnik, J.F., Lanzetta, P., 2010. Ranibizumab (Lucentis) in neovascular age-related macular degeneration: evidence from clinical trials. Br. J. Ophthalmol. 94, 2-13.

Oubraham, H., Cohen, S.Y., Samimi, S., Marotte, D., Bouzaher, I., Bonicel, P., Fajnkuchen, F., Tadayoni, F., 2011. Inject and extend dosing verses dosing as needed: A comparative retrospective study of ranibizumab in exudative age-related macular degeneration. Retina. 31, 26-30.

Regillo, C.D., Brown, D.M., Abraham, P., Yue, H., 2008. On behalf of the PIER study group. Randomized, double-masked, sham-controlled trial of ranibizumab for neovascular age-related macular degeneration: PIER Study year 1. Am. J. Ophthalmol. 145, $239-248$.

Rosenfeld, P.J., Brown, D.M., Heier, J.S., 2006. For the MARINA study Group. Ranibizumab for neovascular age-related macular degeneration. The New England Journal of Medicine. 355, 1419-1431.

Rosenfeld, P.J., Rich, R.M., Lalwani, G.A., 2006. Ranibizumab: Phase III clinical trial results. Opthalmol. Clin. North Am. 19, $361-372$.

Schmidt-Erfurth, U., Eldem, B., Guymer, R., Korobelnik, J.F., Schlingeann, R.O., 2011. on behalh of the EXCITE study group. Efficacy and safety of monthly versus quarterly ranibizumab treatment in neovascular age-related macular degeneration: The EXCITE study. Ophthalmol. 5, 831-839.

Spitzer, M.S., Ziemssen, F., Bartz-Schmidt, K.U., 2008. Treatment of age-related macular degeneration: focus on ranibizumab. Clin. Ophthalmol. 2, 1-14. 